\title{
37 \\ WOMEN'S SAFETY ISSUES IN EXPORT ZONES IN DEVELOPING COUNTRIES IN THE CONTEXT OF A GLOBALISED ECONOMY
}

doi:10.1136/injuryprev-2012-040580a.37

JL LU. National Institutes of Health, University of the Philippine Manila

Background Women dominate the labourforce in export zones which are multinational enclaves in the country. In this type of work, there are reports of safety issues that affect their health.

Objectives This study tried to look into the occupational safety issues of women workers.

Methods This investigated 630 women workers in 31 industries in export zones in the Philippines. Tools included work investigation, industrial hygiene and interviews.

Results The study showed that technology has intensified work. The new work arrangements were seen to produce new hazards. The characteristics now of the new workplace are: information technology intensive work, fast pace of work, the need for upskilling, burnout, chronic sleep debt, and superspeed communications. Accidents were a common sight in factories. The women reported the following accidents in the workplace for the past one-year: eye infection due to dust and wounds due to sharp objects. The more severe forms of accidents were falling (14\%), electrical accidents $(6.3 \%)$ and being caught in the machine (17.3\%). The latter was the most common form of amputation of any body part.

Significance The contribution of this study to the field is to show that with the growing internationalisation of work and economies of nation states, women's involvement in the labour market has increased their vulnerability to hazards and injuries where consequent safety programmes are not implemented. 